\title{
Circulating adipokines and metabolic setting in differentiated thyroid cancer
}

\author{
Chiara Mele ${ }^{1,2}$, Maria Teresa Samà ${ }^{3}$, Alessandro Angelo Bisoffi ${ }^{1}$, Marina Caputo ${ }^{1}$, Valentina Bullara ${ }^{3}$, Stefania Mai ${ }^{4}$, \\ Gillian Elisabeth Walker ${ }^{5}$, Flavia Prodam ${ }^{5}$, Paolo Marzullo ${ }^{1,2}$, Gianluca Aimaretti' ${ }^{1}$ and Loredana Pagano ${ }^{1,6}$ \\ 'Division of Endocrinology, Department of Translational Medicine, University of Piemonte Orientale, Novara, Italy \\ 2Division of General Medicine, Istituto Auxologico Italiano, IRCCS, S. Giuseppe Hospital, Piancavallo di Oggebbio (VB), Italy \\ ${ }^{3}$ Division of Endocrinology, University Hospital 'Maggiore della Carità', Novara, Italy \\ ${ }^{4}$ Laboratory of Metabolic Research, Istituto Auxologico Italiano, IRCCS, S. Giuseppe Hospital, Piancavallo di Oggebbio (VB), Italy \\ ${ }^{5}$ Department of Health Sciences, University of Piemonte Orientale, Novara, Italy \\ ${ }^{6}$ Division of Endocrinology, Diabetology and Metabolism, Department of Medical Sciences, University of Turin, Turin, Italy \\ Correspondence should be addressed to C Mele: chiara.mele1989@gmail.com
}

\begin{abstract}
The associative link relating insulin resistance (IR) and adipokines to the occurrence and phenotype of differentiated thyroid cancer (DTC) is unknown. The aim of this study was to evaluate the relationship between IR and adipokines in DTC patients, as compared with carriers of benign thyroid diseases (BTD) and healthy controls. This observational study enrolled 77 subjects phenotyped as DTC $(N=30)$, BTD $(N=27)$ and healthy subjects $(N=20)$. Each subject underwent preoperative analysis of anthropometric parameters, thyroid function and autoimmunity, insulin resistance (HOMA-IR) and levels of unacylated (UAG) and acylated ghrelin (AG), obestatin, leptin and adiponectin. Multivariate regression models were used to test the predictive role of metabolic correlates on thyroid phenotypes and DTC extension. The three groups showed similar age, gender distribution, smoking habit, BMI and thyroid parameters. Obestatin was significantly higher in DTC group compared to BTD $(P<0.05)$ and control subjects $(P<0.0001)$. DTC and BTD groups showed higher levels of UAG $(P<0.01)$ and AG $(P<0.05)$. Leptin levels were comparable between groups, whereas adiponectin levels were lower in DTC compared to BTD group $(P<0.0001)$ and controls $(P<0.01)$. In parallel, HOMA-IR was higher in DTC than BTD $(P<0.05)$ and control group $(P<0.01)$. Stepwise multivariable regression analysis showed that obestatin and UAG were independent predictors of DTC ( $P=0.01$ for both). In an analysis restricted to the DTC group, obestatin levels were associated with the absence of lymph node metastases $(P<0.05)$. Our results highlight a potential association between metabolic setting, circulating adipokines and thyroid cancer phenotype.
\end{abstract}

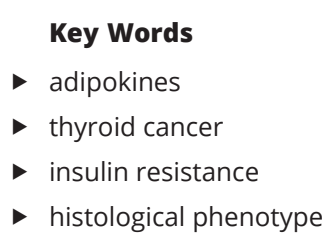

Endocrine Connections (2019) 8, 997-1006

\section{Introduction}

The incidence rates of differentiated thyroid cancer (DTC) have been rising in many countries over the last few decades $(1,2)$ along with a parallel increase in obesity and metabolic disorders (3).

Even if the growing incidence of DTC is at least in part dependent on improved accuracy of diagnostic tools, which likely results in 'over-diagnosis' of microcarcinomas $(1,4,5,6)$, an increasing prevalence of more aggressive forms of DTCs has been highlighted in several studies $(1,7,8)$, suggesting that changes in incidence pattern of DTCs are likely real. An epidemiological link between metabolic derangement associated with excess body weight and thyroid cancers has been highlighted in cross-sectional studies and
This work is licensed under a Creative Commons Attribution-NonCommercial-NoDerivatives 4.0 elpternationab bicense.ifica.com at 04/26/2023 04:22:12AM 
confirmed in meta-analyses of cross-sectional and prospective studies. Many advocate that environmental and lifestyle factors, such as obesity and insulin resistance (IR), could be implicated in the pathogenesis of thyroid cancer $(2,9,10)$. Although the pathways linking obesity and IR to thyroid cancer remain largely unknown, a potential role for insulin, growth hormone (GH) secretagogues and adipokines has been postulated (10). Insulin not only regulates cell metabolism but also stimulates cell growth via its own receptor (IR), and many cancer cells overexpress the A isoform of the IR, which has a predominant mitogenic effect (10). Insulin and hyperinsulinaemia could thus exert oncogenic potential via abnormal stimulation of multiple cellular signalling cascades, enhancing growth factor-dependent cell proliferation and/or by directly affecting cell metabolism (11). Other factors potentially implicated in the loop linking obesity and IR to DTC could be represented by ghrelin, an orexigenic hormone capable of GH secretagogue activity and obestatin, which is encoded by the same gene-encoding ghrelin but shows opposing effects on GH secretion and appetite $(10,12)$. Both are expressed in papillary thyroid cancer tissues, albeit with inhomogeneous patterns (12). Further, there is evidence that the adipocytokine network could play a role in thyroid tumorigenesis. Leptin, food intake and resting energy expenditure also plays a role in activating monocytes and macrophages and can stimulate angiogenesis and cell proliferation $(13,14)$. The effect of leptin has been investigated in thyroid cancer cells (10), and it has been shown to promote cell migration in PTC cells (15) while stimulating a more aggressive cancer phenotype (16) and promoting the de-differentiation of thyroid cancer cells (17). Another potentially relevant adipokine is adiponectin known for its ability to improve insulin sensitivity, which influences cell proliferation and regulates the balance of anti- and pro-inflammatory molecules at the cellular level $(9,18)$. Serum adiponectin levels have been found to be inversely correlated with the presence of DTC (19), while the absence of adiponectin receptors on DTC cells has been associated with extrathyroidal extension, multicentricity and higher tumour-node-metastases (TNM) stage of DTCs (20).

To date, the association relating IR and adipokines to the presence and phenotype of DTC is not completely clear and is still debated. Therefore, the aim of our observational study was to evaluate the relationship between IR and adipokines in DTC patients, as compared with carriers of BTD and subjects without thyroid diseases.

\section{Materials and methods}

\section{Patients}

The study enrolled 77 subjects, consisting of 57 adults undergoing total thyroidectomy because of benign thyroid disease (uninodular or multinodular goitre, follicular adenoma) or suspected DTC on the basis of cytological examination according to Bethesda criteria (21) and classified as TIR3B, TIR4, TIR5. Twenty healthy subjects without thyroid disease served as control group.

Following blood sampling for the purpose of the study, patients who underwent thyroidectomy were divided into two groups, according to the post-surgical histological diagnosis:

- DTC group: 30 patients diagnosed with papillary or follicular thyroid cancer

- BTD group: 27 patients diagnosed with benign thyroid diseases.

Subjects with poorly differentiated, anaplastic, medullary thyroid carcinomas, secondary tumours, history of medical neck irradiation, hormone therapies and treatments interfering with insulin sensitivity were excluded from the analysis.

The experimental procedure was approved by the ad hoc Ethical Research Committee of Novara, Italy. A written informed consent was obtained from all patients and controls. The study protocol was conformed to the guidelines of the European Convention on Human Rights and Biomedicine concerning biomedical research.

\section{Body measurements}

All subjects underwent body measurements wearing light underwear, in fasting conditions after voiding. Weight and height were measured in the nearest $0.1 \mathrm{~kg}$ and $0.1 \mathrm{~cm}$, respectively, using standard methods. BMI was expressed as body mass $(\mathrm{kg}) /$ height $(\mathrm{m})^{2}$. Overweight was defined for any BMI between 25 and $29.9 \mathrm{~kg} / \mathrm{m}^{2}$ and obesity for any BMI over $30 \mathrm{~kg} / \mathrm{m}^{2}$. Waist circumference (WC) was measured midway between the lowest rib and the top of the iliac crest after gentle expiration.

\section{Laboratory tests}

Blood samples were preoperatively drawn under fasting conditions, centrifugated and stored at $-20^{\circ} \mathrm{C}$ or $-80^{\circ} \mathrm{C}$, until assay. The protease inhibitor aprotinin was added to plasma aliquots for determination of ghrelin concentrations. 
Undiluted serum samples were assayed for thyroidstimulating hormone (TSH), free thyroxine (fT4) and free triiodothyronine (fT3) using an automated chemiluminescence assay system (ADVIA Centaur Systems TSH3/fT4/fT3 Ultra Ready Pack, Siemens Healthcare Diagnostics).

Serum levels of thyroglobulin $(\mathrm{Tg})$ were determined using an automated chemiluminescence method (LIAISON XL, DiaSorin S.p.A, Saluggia).

Plasma levels of anti-Tg and anti-thyroperoxidase (TPO) antibodies were assessed using an automated chemiluminescence assay system (Anti-Tg, Anti-TPO Ready Pack, Siemens Healthcare Diagnostics).

Plasma glucose levels were determined using an enzymatic method (ADVIA 1800 Chemistry System, Siemens Healthineers). Serum insulin levels were obtained using direct chemiluminescence method (ADVIA Centaur IRI, Siemens). Insulin resistance was calculated by the homeostatic model of insulin resistance (HOMA-IR) index: insulin $(\mathrm{mIU} / \mathrm{mL}) \times($ glucose $(\mathrm{mmol} / \mathrm{L}) / 22.5)(22)$. A HOMA-IR value greater than 2.5 was considered indicative of insulin resistance (23).

For hormone assays, procedures were performed in accordance with the manufacturers' instruction and the samples were analysed in duplicate.

Serum leptin levels were assessed using a commercially available human ELISA kit (Mediagnost, Reutlinger, Germany). Intra-assay CV and inter-assay CV of leptin were less than $10 \%$. Minimum detectable concentration was $0.2 \mathrm{ng} / \mathrm{mL}$.

Serum adiponectin levels were determined using a commercially available human ELISA kit (Mediagnost, Reutlinger, Germany). Intra-assay $\mathrm{CV}$ was less than $6.7 \%$ and inter-assay $\mathrm{CV}$ was less than $4.7 \%$. Minimum detectable concentration was $0.6 \mathrm{ng} / \mathrm{mL}$.

Serum obestatin concentrations were assessed using a commercially available human EIA kit (Yanaihara Institute Inc, Awakura, Japan). Intra-assay CV was 3.5-9.9\% and inter-assay CV was $5.6-9.0 \%$. Minimum detectable concentration was $0.231 \mathrm{ng} / \mathrm{mL}$.

Plasma unacylated ghrelin (UAG) levels were determined using a commercially available human ELISA kit (BioVendor Research and Diagnostic Product, Czech Republic). Intra-assay CV was $3.2-11.8 \%$ and inter-assay $\mathrm{CV}$ was $3.8-13.2 \%$. Minimum detectable concentration was $6 \mathrm{pg} / \mathrm{mL}$.

Plasma acylated ghrelin (AG) levels were assessed using a commercially available human ELISA kit (BioVendor). Intra-assay CV was $2.9-11.8 \%$ and inter-assay $\mathrm{CV}$ was 3.4-14.4\%. Minimum detectable concentration was $5 \mathrm{pg} / \mathrm{mL}$.

\section{Thyroid cytology and histology}

The cytology specimens were evaluated and classified according to the international guidelines $(24,25)$. Histological slides were reviewed by two independent pathologists for the purpose of this study. For all cases, tumour-associated thyroiditis was assessed. The tumour size, number of foci, focality, extension, presence of locoregional and/or distant metastases were also reported and classified according to the 2010 TNM system (26).

\section{Neck ultrasound (US)}

Pre-surgical US was routinely performed in all patients. The study was conducted using a 'My Lab 25 Gold' (ESAOTE S.p.A, Genova, Italy) equipped with a linear transducer of $7.5 \mathrm{MHz}$. Sonographic features predictive of malignancy were considered according to American Thyroid Association and AACE-AME guidelines $(24,27)$. Cervical lymphadenopathies and their US features were also evaluated.

\section{Data analysis}

Statistical analysis was performed using SPSS version 21 on $\log$ transformed data to correct for the non-Gaussian distribution obtained by the Shapiro-Wilk test. Values were expressed as median and interquartile ranges (IQ). For comparative analysis, ANOVA between the three groups was used. Spearman's correlation analysis was used to identify significant associations between variables of interest. ANCOVA multinomial regression analysis was used to evaluate the association of adipokines levels with histological characteristics of DTCs. Stepwise multivariate regression analysis was used to evaluate the independent association of metabolic, anthropometric or biochemical parameters with adipokines and HOMA-IR. $\beta$ coefficients and related significance values obtained from the models were reported. $P<0.05$ was considered as statistically significant.

\section{Results}

\section{Analysis on all study groups}

The anthropometric and biochemical data of our population are reported in Table 1.

Anthropometric parameters were comparable between the groups. Obesity (BMI $>30 \mathrm{~kg} / \mathrm{m}^{2}$ ) was present in 16 cases (six patients with DTC, eight patients with 
BTD and two controls) and overweight in 21 cases (seven patients with DTC, six patients with BTD and eight controls). Before surgery, hypothyroidism under replacement therapy was present in eight patients (six patients with DTC and two patients with BTD), while hyperthyroidism under methimazole treatment was present in three patients with BTD.

Thyroid function parameters were comparable between the groups, whereas TPOAb levels were higher in DTC and BTD group with respect to the control group $(P<0.05)$

Compared to controls, we observed higher levels of UAG $(P<0.01$ for both) and AG $(P<0.05$ for both) in DTC and BTD groups. Obestatin concentrations were higher in DTC group as compared both to BTD group $(P<0.05)$ and controls $(P<0.0001)$, as well as in the BTD group with respect to controls $(P<0.0001)$. Leptin levels were comparable between the three groups, whereas adiponectin levels were lower in DTC group compared to
BTD group $(P<0.0001)$ and controls $(P<0.01)$, and in BTD group with respect to controls $(P<0.0001)$.

Analysis of metabolic parameters showed the occurrence of IR in 25 cases of the entire dataset (14 patients with DTC, 8 patients with BTD and 3 controls). Among subjects with IR, 18 were overweight/obese. The DTC group showed higher insulin levels and HOMA-IR than BTD (insulin: $P<0.01$, HOMA-IR: $P<0.05$ ) and control group (insulin: $P<0.01$, HOMA-IR: $P<0.01$ ).

In bivariate correlation analysis across the three groups (Table 2), expected positive associations were documented between metabolic parameters, HOMA-IR and leptin levels. Both leptin and adiponectin were positively correlated with anti-TG antibodies, while adiponectin was also correlated with AbTPO levels. However, the above mentioned correlations were lost after controlling for age, gender, BMI and thyroid phenotypes.

Stepwise multivariable regression analysis with a model weighted for gender, age, BMI, WC and HOMA-IR

Table 1 Anthropometric and biochemical data obtained in the two groups and controls.

\begin{tabular}{|c|}
\hline Parameters (median (IQ)) \\
\hline Gender \\
\hline No. of males \\
\hline No. of females \\
\hline Age (years) \\
\hline Smokers \\
\hline Never \\
\hline Current \\
\hline Former \\
\hline Weight (kg) \\
\hline $\mathrm{BMI}\left(\mathrm{kg} / \mathrm{m}^{2}\right)$ \\
\hline$W C(\mathrm{~cm})$ \\
\hline $\mathrm{TSH}(\mu \mathrm{IU} / \mathrm{mL})$ \\
\hline fT4 (ng/dL) \\
\hline fT3 (pg/mL) \\
\hline TG $(n g / d L)$ \\
\hline TGAb (IU/mL) \\
\hline TPOAb (IU/mL) \\
\hline Glucose (mg/dL) \\
\hline Insulin (mIU/mL) \\
\hline HOMA-IR \\
\hline UAG (pg/mL) \\
\hline $\mathrm{AG}(\mathrm{pg} / \mathrm{mL})$ \\
\hline Obestatin (ng/mL) \\
\hline Leptin $(\mathrm{ng} / \mathrm{mL})$ \\
\hline Adiponectin $(\mu \mathrm{g} / \mathrm{mL})$ \\
\hline
\end{tabular}

Controls $(n=20)$
5
15
$47.0(37.0-62.5)$

24
3
3

$69.5(58.0-73.3)$

$25.1(22.7-26.4)$

$86.5(78.8-90.0)$

$1.6(1.2-2.1)$

$1.2(1.1-1.3)$

$3.1(3.0-3.3)$

$17.2(9.4-30.5)$

$34.5(21.3-52.0)$

$33.0(21.0-49.5)$

86.0 (83.5-94.5)

$8.1(6.5-10.1)$

$1.6(1.4-2.2)$

$21.7(11.8-30.8)$

$4.3(2.4-6.2)$

$2.5(2.2-2.6)$

$10.6(5.7-25.6)$

$31.4(15.2-41.0)$

\begin{tabular}{|c|}
\hline BTD group $(n=27)$ \\
\hline 4 \\
\hline 23 \\
\hline $56.0(53.5-65.0)$ \\
\hline 17 \\
\hline 5 \\
\hline 5 \\
\hline $62.0(58.0-80.5)$ \\
\hline $25.8(21.9-30.3)$ \\
\hline $90.0(76.0-99.5)$ \\
\hline $1.3(1.0-2.0)$ \\
\hline $1.1(1.0-1.3)$ \\
\hline $3.4(2.8-3.5)$ \\
\hline $43.3(15.7-220.9)^{b}$ \\
\hline $32.2(15.0-54.5)$ \\
\hline $41.2(32.9-134.9)^{a}$ \\
\hline $90.0(81.5-98.0)$ \\
\hline $7.5(5.8-11.5)$ \\
\hline $1.6(1.3-2.6)$ \\
\hline $79.2(39.0-129.8)^{b}$ \\
\hline $9.0(5.3-16.5)^{a}$ \\
\hline $4.6(4.2-5.0)^{c}$ \\
\hline $16.8(13.2-23.1)$ \\
\hline $22.2(17.7-31.1)$ \\
\hline
\end{tabular}

\begin{tabular}{c}
\hline DTC group $(n=30)$ \\
9 \\
21 \\
$50.0(41.0-58.8)$
\end{tabular}

Data are expressed as median (with interquartile range in parentheses). Comparison between populations was performed by ANOVA test and $\chi^{2}$ test. Significant differences are shown in bold characters. Significant differences between controls and BTD or DTC group: ${ }^{a} P<0.05,{ }^{b} P<0.01,{ }^{c} P<0.0001$. Significant differences between BTD and DTC group: ${ }^{\mathrm{d}} P<0.05,{ }^{\mathrm{e}} P<0.01,{ }^{\mathrm{f}} P<0.0001$.

AG, acylated ghrelin; BMI, body mass index; fT3, free triiodothyronine; fT4, free thyroxine; HOMA-IR, Homeostatic Model of Insulin Resistance; TG, thyroglobulin; TGAb, Anti-thyroglobulin antibodies; TPOAb, anti-thyroperoxidase antibodies; TSH, thyroid-stimulating hormone; UAG, unacylated ghrelin; WC, waist circumference.

https://ec.bioscientifica.com https://doi.org/10.1530/EC-19-0262 (c) 2019 The authors Published by Bioscientifica Ltd

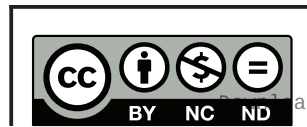

This work is licensed under a Creative Commons Attribution-NonCommercial-NoDerivatives 4.0 Internationab bicense.ifica . com at $04 / 26 / 2023 \quad 04: 22: 12$ AM 
Table 2 Spearman's correlation analysis between adipokines levels, HOMA-IR and anthropometric-biochemical parameters in the population as a whole.

\begin{tabular}{|c|c|c|c|c|c|c|}
\hline $\begin{array}{l}\text { Variables } \\
\text { (correlation coefficient) }\end{array}$ & UAG (pg/mL) & $\mathbf{A G}(\mathrm{pg} / \mathrm{mL})$ & Obestatin $(\mathrm{ng} / \mathrm{mL})$ & Leptin (ng/mL) & Adiponectin $(\mu \mathrm{g} / \mathrm{mL})$ & HOMA-IR \\
\hline Gender & 0.069 & 0.255 & 0.056 & $0.312^{b}$ & -0.042 & -0.150 \\
\hline Age & -0.154 & -0.125 & -0.151 & $0.363^{b}$ & 0.194 & $0.273^{a}$ \\
\hline BMI $\left(\mathrm{kg} / \mathrm{m}^{2}\right)$ & -0.160 & -0.079 & -0.098 & $0.606^{c}$ & -0.026 & $0.561^{c}$ \\
\hline WC (cm) & -0.037 & -0.024 & -0.140 & $0.585^{c}$ & -0.154 & $0.598^{c}$ \\
\hline Glucose (mg/dL) & -0.017 & -0.075 & 0.079 & $0.304^{b}$ & 0.210 & $0.509^{c}$ \\
\hline Insulin (mIU/mL) & -0.236 & -0.213 & -0.178 & $0.453^{c}$ & $-0.279^{a}$ & $0.953^{c}$ \\
\hline HOMA-IR & -0.202 & -0.208 & -0.138 & $0.453^{c}$ & -0.195 & - \\
\hline TSH $(\mu \mathrm{IU} / \mathrm{mL})$ & -0.008 & -0.090 & 0.087 & -0.014 & -0.049 & 0.068 \\
\hline fT4 (ng/dL) & 0.101 & 0.138 & -0.125 & 0.051 & 0.083 & -0.007 \\
\hline fT3 (pg/mL) & -0.161 & -0.099 & 0.007 & 0.006 & 0.028 & -0.067 \\
\hline TG (ng/dL) & -0.126 & -0.080 & -0.022 & -0.045 & 0.234 & -0.191 \\
\hline TgAb (IU/mL) & 0.032 & 0.045 & -0.031 & $0.263^{a}$ & $0.374^{b}$ & 0.182 \\
\hline TPOAb (IU/mL) & 0.258 & 0.241 & 0.072 & 0.161 & $0.289^{a}$ & 0.043 \\
\hline
\end{tabular}

Significant correlations are written in bold. For significance: ${ }^{a} p<0.05,{ }^{b} p<0.01,{ }^{c} p<0.0001$.

BMI, body mass index; fT3, free triiodothyronine; fT4, free thyroxine; HOMA-IR, Homeostatic Model of Insulin Resistance; TG, thyroglobulin; TGAb, anti-thyroglobulin antibodies; TPOAb, anti-thyroperoxidase antibodies; TSH, thyroid-stimulating hormone; WC, waist circumference.

documented that the presence of DTC (DTC $=0$, $\mathrm{BTD}=1$, controls $=2$ ) was independently predicted by obestatin and UAG levels (respectively $\beta=-0.339$ and $\beta=-0.357, P=0.01)$.

\section{Analysis of patients with DTC}

Histopathological characteristics of all patients with DTC are summarised in Table 3.

As expected, the most frequent histotype was PTC (25/30 cases) and the most common variant was the classical one ( $9 / 30$ cases), followed by other more aggressive variants such as tall cell, oncocytic, solid and Warthin-like variants. Capsular invasion was present in 13/30 cases, while bilaterality and multifocality were described in 5/30 and $8 / 30$ patients, respectively. Overall, 18/30 tumours were classified as stage I, followed by stage IV (5/30). Among patients who underwent lymph node dissection, seven patients had lymph node metastases. Lastly, tumourassociated thyroiditis was found in 7/30 cases.

Bivariate correlation analysis restricted to the DTC group is reported in Table 4. After adjusting for age, BMI, WC and gender, only the negative association between obestatin levels and the presence of lymph node metastases $(r=-0.862$, $P<0.05)$ and the positive association between obestatin and TPOAb titer $(r=0.856, P<0.05)$ remained significant.

Logistic regression analysis, performed to study the association between adipokines levels or HOMA-IR and DTC histological characteristics, showed that obestatin levels were significantly associated with the absence of lymph node metastases (odds ratio $(\mathrm{OR})=4.370$, CI $95 \%$ $1.080-10.964, P<0.05)$.

\section{Discussion}

The present study analysed the association relating IR and multiple adipokines with DTC phenotypes. Our results showed that the prevalence of IR was higher in patients with DTC and that these subjects harbour higher level of obestatin than patient with benign nodules and controls. However, in the analysis restricted to DTC cases, obestatin levels were inversely associated with the metastatic capacity of tumour. While leptin levels were comparable between groups, adiponectin levels were lower in patients with DTC in respect to subjects with benign nodules and controls. Moreover, in patients with either benign or malignant thyroid nodules, higher concentrations of UAG and AG were observed as compared to controls. Higher obestatin and UAG levels were also associated with the presence of malignancy in patients with thyroid nodules.

In the past few decades, the incidence of DTC has shown a steady increase worldwide $(2,8)$. Some evidence suggests that environmental and lifestyle factors can play an important role $(2,28)$. Among the potential risk factors involved in the changing epidemiology of TC, particular attention has been accorded to IR and the metabolic syndrome, which have been also rapidly increasing worldwide due to widespread dietary and lifestyle changes (29). On this basis, it has been suggested that IR is associated with the rising incidence of DTCs. A small
This work is licensed under a Creative Commons Attribution-NonCommercial-NoDerivatives 4.0 Internationab License.ifica. com at $04 / 26 / 2023$ 04:22:12AM 
Table 3 Histopathological characteristics of all patients with DTC.

\begin{tabular}{|c|c|}
\hline & $\begin{array}{l}\text { N. of patients } \\
\text { (30 cases) }\end{array}$ \\
\hline \multicolumn{2}{|l|}{ Cytology } \\
\hline Not performed & 1 \\
\hline Thy 2 & 1 \\
\hline Thy $3 f$ & 1 \\
\hline Thy 4 & 5 \\
\hline Thy 5 & 1 \\
\hline \multicolumn{2}{|l|}{ Histotype } \\
\hline PTC & 25 \\
\hline FTC & 5 \\
\hline \multicolumn{2}{|l|}{ PTC variant } \\
\hline Classical & 9 \\
\hline Follicular & 5 \\
\hline Classical and follicular & 5 \\
\hline Other & 6 \\
\hline \multicolumn{2}{|l|}{ FTC variant } \\
\hline Minimally invasive & 4 \\
\hline Invasive & 1 \\
\hline \multicolumn{2}{|l|}{ Tumour size $(\mathrm{cm})$} \\
\hline$\leq 1 \mathrm{~cm}$ & 6 \\
\hline $1.0-2.0 \mathrm{~cm}$ & 11 \\
\hline $2.0-4.0 \mathrm{~cm}$ & 11 \\
\hline$>4 \mathrm{~cm}$ & 2 \\
\hline \multicolumn{2}{|l|}{ Multifocality } \\
\hline Present & 8 \\
\hline \multicolumn{2}{|l|}{ Bilaterality } \\
\hline Present & 5 \\
\hline \multicolumn{2}{|l|}{ Thyroid capsular invasion } \\
\hline Present & 13 \\
\hline \multicolumn{2}{|l|}{ Staging (TNM 2010) } \\
\hline Stage I & 18 \\
\hline Stage II & 4 \\
\hline Stage III & 3 \\
\hline Stage IV & 5 \\
\hline \multicolumn{2}{|l|}{ Histological associated thyroiditis } \\
\hline Present & 7 \\
\hline \multicolumn{2}{|l|}{ Lymph node metastases } \\
\hline Present (18 lymphadenectomy) & 7 \\
\hline
\end{tabular}

FTC, follicular thyroid cancer; PTC, papillary thyroid cancer.

cross-sectional study detected an increased prevalence of IR in patients with DTC (30), and a recent study by Bae et al. (31) showed a clear-cut association relating insulin and HOMA-IR index to the risk of PTC and the multifocality of this disease. Our results reflected these findings. In fact, we found that patients with DTC harbour higher insulin levels and HOMA-IR index with respect to patients with benign nodules and subjects without thyroid diseases. IR is known to be an important risk factor responsible for carcinogenesis (32). However, we failed to demonstrate the direct associations between insulin levels and DTC, suggesting that the metabolic setting rather than insulin levels could play a role in this relationship. This circumstance would agree with the evidence that
IR enhances the pro-inflammatory state by decreasing the production of anti-inflammatory adipokines, such as adiponectin, and increasing the production of proinflammatory adipokines, such as leptin, which could interact with molecular pathways involved in tumour development (33).

Adipokines are a subset of cytokines produced by the adipose tissue (34). They are involved not only in immune responses, but also in the regulation of appetite and energy balance, insulin sensitivity, angiogenesis, blood pressure regulation and lipid metabolism (14). In particular, leptin is involved in the control of food intake through satiety sensation, regulation of energy expenditure, activation of monocytes and macrophages, stimulation of VEGF, angiogenesis, cell proliferation and suppression of antiinflammatory cytokines. A relationship of this molecule with DTC and other cancers has been demonstrated (35, 36). With regard to DTC, leptin was previously found to be associated with a high risk of lymph node metastases (37), and it seems to be involved in the clinical phenotype of the tumours as well as in the migration of thyroid cell, promoting metastases formation and diffusion $(15,17,38,39,40)$. Although our study failed to detect differences in serum leptin levels across the three groups, we observed a significant association between circulating leptin and the presence of lymph node metastases, which was lost after controlling for confounders (age, BMI and gender). However, it is worth considering that the serum concentration of leptin may not reflect its action on thyroid tissue. The higher levels of this adipokine found in subjects with benign nodules, would require future analysis to evaluate its modulatory role in the hyperplastic phase of the thyroid follicle.

Adiponectin is an adipokine with strong antiinflammatory properties. It is able to improve insulin sensitivity, influence cell proliferation and regulate the balance of anti- and pro-inflammatory molecules and cells $(41,42,43)$. Owing to its complex anti-proliferative and inflammation-restraining functions, adiponectin has been suggested to have anti-neoplastic properties in some types of cancers (9). Our results showed lower adiponectin levels in patients with thyroid cancer. Similar findings were shown by Mitsiades et al. (19) who demonstrated that serum adiponectin levels are inversely associated with the prevalence of DTCs, suggesting a potential protective effect of adiponectin against the development of this cancer. The mechanisms by which adiponectin may act on thyroid cancer still remain to be identified, but it may include a protection against the development of IR (44), in particular through the activation of the 
Table 4 Spearman's correlation analysis between adipokines levels and tumour characteristics and thyroid biochemical parameters in patients with DTC.

\begin{tabular}{l} 
Variables (correlation \\
coefficient) \\
\hline Tumour size \\
Histotype $^{b}$ \\
PTC variants \\
Bilaterality \\
Multifocality \\
Thyroid capsular invasion \\
Lymph node metastases \\
Histological associated \\
thyroiditis \\
Staging \\
TSH \\
fT4 \\
fT3 \\
Tg \\
TgAB \\
TPOAb
\end{tabular}

$\begin{array}{r}\hline \text { UAG }(\mathrm{pg} / \mathrm{mL}) \\ \hline 0.110 \\ -0.028 \\ 0.156 \\ -0.254 \\ -0.089 \\ -0.333 \\ -0.056 \\ -0.292 \\ -0.314 \\ -0.222 \\ 0.197 \\ -0.189 \\ -0.089 \\ 0.017 \\ 0.279 \\ \hline\end{array}$

\begin{tabular}{c}
\hline AG $(\mathrm{pg} / \mathrm{mL})$ \\
\hline-0.004 \\
0.000 \\
0.101 \\
-0.085 \\
0.022 \\
-0.210 \\
-0.280 \\
-0.280 \\
\\
-0.340 \\
-0.105 \\
0.128 \\
-0.104 \\
-0.230 \\
0.007 \\
0.300 \\
\hline
\end{tabular}

\begin{tabular}{c}
\hline Obestatin $(\mathrm{ng} / \mathrm{mL})$ \\
\hline $\mathbf{0 . 4 9 7 ^ { a }}$ \\
-0.094 \\
0.079 \\
0.158 \\
0.227 \\
0.136 \\
$-\mathbf{0 . 7 7 9}$ \\
-0.227 \\
0.272 \\
0.193 \\
-0.159 \\
-0.095 \\
0.210 \\
-0.202 \\
-0.256 \\
\hline
\end{tabular}

\begin{tabular}{c}
\hline Leptin $(\mathrm{ng} / \mathrm{mL})$ \\
\hline-0.250 \\
-0.175 \\
-0.011 \\
0.316 \\
0.194 \\
0.207 \\
$-\mathbf{0 . 4 3 9}$ \\
$\mathbf{0 . 5 0 1}$ \\
\\
-0.044 \\
0.090 \\
0.145 \\
-0.213 \\
-0.229 \\
$\mathbf{0 . 4 4 3}$ \\
0.333 \\
\hline
\end{tabular}

\begin{tabular}{c}
\hline Adiponectin $(\mu \mathrm{g} / \mathrm{mL})$ \\
\hline 0.303 \\
0.323 \\
0.306 \\
-0.022 \\
0.231 \\
-0.091 \\
0.187 \\
0.106 \\
\\
0.180 \\
-0.120 \\
-0.084 \\
-0.151 \\
0.043 \\
0.281 \\
0.250
\end{tabular}

$\begin{array}{r}\hline \text { HOMA-IR } \\ \hline-0.149 \\ -0.109 \\ -0.142 \\ 0.164 \\ 0.074 \\ 0.124 \\ 0.073 \\ 0.308 \\ \\ 0.223 \\ 0.111 \\ -0.168 \\ -0.275 \\ -0.046 \\ 0.307 \\ -0.082 \\ \hline\end{array}$

${ }^{a} P<0.05,{ }^{d} P<0.01$. ${ }^{b} P T C=0, F T C=1 ;{ }^{c}$ classical $=0$, follicular $=1$, classical and follicular $=2$, other variants $=3$.

fT3, free triiodothyronine; fT4, free thyroxine; PTC, papillary thyroid cancer; Tg, thyroglobulin; TGAb, anti-thyroglobulin antibodies; TPOAb, antithyroperoxidase antibodies; TSH, thyroid-stimulating hormone.

adenosine monophosphate kinase (AMPK) pathway (20, 45 , 46). Adiponectin has also been shown to directly inhibit angiogenesis and promote apoptosis in vivo, through the activation of the caspase cascade (47). Low adiponectin has been proposed as a possible mediator in the association between BMI and cancer risk (48).

Ghrelin is implicated in several processes of cancer progression including cell proliferation, cell migration and invasion, angiogenesis and apoptosis, probably via an autocrine/paracrine mechanism (49). Some reports demonstrated that ghrelin may have an inhibitory effect in the proliferation of some cancer types, including thyroid, prostate, breast and small-cell lung carcinoma (50). However, the exact role of ghrelin in thyroid tumorigenesis is still debated. Ucan and colleagues (49) did not found any significant differences in serum ghrelin levels between patients with PTC and healthy controls. Our study demonstrated that AG concentrations were higher in the patients with malignant and benign thyroid nodules with respect to controls. These findings seem to support the hypothesised role of AG in promoting tumorigenesis $(51,52)$. In particular, the increased expression of this molecule could influence thyroid tumor proliferation through deregulation of $\mathrm{GH}$ and IGF-1 secretion - factors involved in cancer growth (53).

With regard to UAG, our data showed that this hormone was higher in patients with DTC and benign thyroid nodules. Moreover, we found that the presence of DTC was independently predicted by UAG.
Recently, UAG has been hypothesised to be involved in various biological activities, including the inhibitory role on AG (54), the anti-proliferative and pro-apoptotic capacity on different cell lines in vitro (55). However, these are preliminary results and its role is still debated. Further prospective studies investigating ghrelin expression in DTCs and its association with serum ghrelin levels could be helpful to clarify this issue.

Finally, the role of obestatin in promoting thyroid cancer tumorigenesis is still controversial. However, this molecule appears very interesting for its probable involvement in cell proliferation through AKT-dependent signalling $(50,56,57)$. In previous studies, Volante et al. (58) found obestatin expression in medullary, papillary, follicular and poorly differentiated thyroid cancer. The authors detected obestatin immunoreactivity mostly in ghrelin-positive areas of DTC, whereas there was no obestatin expression in normal thyroid tissue (58). On the contrary, Karaoglu et al. demonstrated obestatin expression in healthy thyroid, Hashimoto thyroiditis and PTC without evident differences in the intensity of reaction (12). In a recent study, obestatin immunoreactivity was observed in benign nodules, as well as cancer cells (59). However, the intensity of immunohistochemical expression was poor and obestatin-positive cells were accompanied by regions without any immunoreactivity (58). In our study, serum obestatin concentrations were, overall, higher in patients with DTC with respect to subjects with BTD and controls, thus representing a predictor of the presence of DTC.

This work is licensed under a Creative Commons Attribution-NonCommercial-NoDerivatives 4.0 Internationab ticense.ifica.com at 04/26/2023 04:22:12AM 


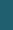

Interestingly, within the DTC group obestatin levels were significantly associated with the absence of lymph node metastases. Together, our data suggest a potential dual role for obestatin, such that its circulating levels could represent a biomarker of the metabolic setting of DTC, but at the same time, this adipokine could reflect lower proneness to the metastatic diffusion of DTC.

Our study has several limitations which have to be pointed out. First, the small patient population and the associative nature of the study do not allow us to draw any conclusion about the mechanisms involved in the association between IR, adipokines and DTC tumorigenesis. Second, we did not perform any analysis on the tissue expression of adipokines.

In conclusion, our study highlighted a potential association between metabolic setting, circulating adipokines and thyroid cancer phenotype. An IR-metabolic phenotype and its related biomarkers could influence the pathogenesis of nodular goitre and thyroid cancer. Further studies are awaited to clarify the role of adipokines and metabolic setting in determining DTC phenotype and tumorigenesis.

\section{Declaration of interest}

The authors declare that there is no conflict of interest that could be perceived as prejudicing the impartiality of the research reported.

\section{Funding}

This research did not receive any specific grant from any funding agency in the public, commercial or not-for-profit sector.

\section{Author contribution statement}

$C M, M T S$ and $L P$ designed the study and wrote the main manuscript text; S M and G W performed biochemical assays; A A B, M C and $\checkmark B$ recruited patients and managed the dataset; $G A, P M$ and $F$ performed data analysis and critical overview. All authors reviewed the manuscript.

\section{Acknowledgements}

The authors thank Stefania Moia, Marilisa De Feusis, Marta Roccio (Department of Health Sciences, University of Piemonte Orientale, Novara, Italy) and Roberta Vietti (Laboratory of Metabolic Research, Istituto Auxologico Italiano, Piancavallo (VB), Italy) for laboratory assistance.

\section{References}

1 Pazaitou-Panayiotou K, Iliadou PK, Chrisoulidou A, Mitsakis P, Doumala E, Fotareli A, Boudina M, Mathiopoulou L, Patakiouta F \& Tziomalos $\mathrm{K}$. The increase in thyroid cancer incidence is not only due to papillary microcarcinomas: a 40-year study in 1778 patients. Experimental and Clinical Endocrinology and Diabetes 2013121 397-401. (https://doi.org/10.1055/s-0033-1345125)
2 Pagano L, Mele C, Arpaia D, Samà MT, Caputo M, Ippolito S, Peirce C, Prodam F, Valente G, Ciancia G, et al. How do etiological factors can explain the different clinical features of patients with differentiated thyroid cancer and their histopathological findings? Endocrine 2017 56 129-137. (https://doi.org/10.1007/s12020-016-0992-8)

3 Pazaitou-Panayiotou K, Polyzos SA \& Mantzoros CS. Obesity and thyroid cancer: epidemiologic associations and underlying mechanisms. Obesity Reviews 201314 1006-1022. (https://doi. org/10.1111/obr.12070)

4 Elisei R, Molinaro E, Agate L, Bottici V, Masserini L, Ceccarelli C, Lippi F, Grasso L, Basolo F, Bevilacqua G, et al. Are the clinical and pathological features of differentiated thyroid carcinoma really changed over the last 35 years? Study on 4187 patients from a single Italian institution to answer this question. Journal of Clinical Endocrinology and Metabolism 201095 1516-1527. (https://doi. org/10.1210/jc.2009-1536)

5 Lee TJ, Kim S, Cho HJ \& Lee JH. The incidence of thyroid cancer is affected by the characteristics of a healthcare system. Journal of Korean Medical Science 201227 1491-1498. (https://doi.org/10.3346/ jkms.2012.27.12.1491)

6 Grodski S, Brown T, Sidhu S, Gill A, Robinson B, Learoyd D, Sywak M, Reeve T \& Delbridge L. Increasing incidence of thyroid cancer is due to increased pathologic detection. Surgery 2008 144 1038-1043; discussion 1043. (https://doi.org/10.1016/j. surg.2008.08.023)

7 Gomez Segovia I, Gallowitsch HJ, Kresnik E, Kumnig G, Igerc I, Matschnig S, Stronegger WJ \& Lind P. Descriptive epidemiology of thyroid carcinoma in Carinthia, Austria: 1984-2001. Histopathologic features and tumor classification of 734 cases under elevated general iodination of table salt since 1990: population-based age-stratified analysis on thyroid carcinoma incidence. Thyroid 200414 277-286. (https://doi.org/10.1089/105072504323030933)

8 Enewold L, Zhu K, Ron E, Marrogi AJ, Stojadinovic A, Peoples GE $\&$ Devesa SS. Rising thyroid cancer incidence in the United States by demographic and tumor characteristics, 1980-2005. Cancer Epidemiology, Biomarkers and Prevention 200918 784-791. (https:// doi.org/10.1158/1055-9965.EPI-08-0960)

9 Marcello MA, Cunha LL, Batista FA \& Ward LS. Obesity and thyroid cancer. Endocrine-Related Cancer 201421 T255-T271. (https://doi. org/10.1530/ERC-14-0070)

10 Santini F, Marzullo P, Rotondi M, Ceccarini G, Pagano L, Ippolito S, Chiovato L \& Biondi B. Mechanisms in endocrinology: the crosstalk between thyroid gland and adipose tissue: signal integration in health and disease. European Journal of Endocrinology 2014171 R137-R152. (https://doi.org/10.1530/EJE-14-0067)

11 Almquist M, Johansen D, Björge T, Ulmer H, Lindkvist B, Stocks T, Hallmans G, Engeland A, Rapp K, Jonsson H, et al. Metabolic factors and risk of thyroid cancer in the Metabolic syndrome and Cancer project (Me-Can). Cancer Causes and Control 201122 743-751. (https://doi.org/10.1007/s10552-011-9747-2)

12 Karaoglu A, Aydin S, Dagli AF, Cummings DE, Ozercan IH, Canatan H \& Ozkan Y. Expression of obestatin and ghrelin in papillary thyroid carcinoma. Molecular and Cellular Biochemistry 2009 323 113-118. (https://doi.org/10.1007/s11010-008-9969-0)

13 Piya MK, McTernan PG \& Kumar S. Adipokine inflammation and insulin resistance: the role of glucose, lipids and endotoxin. Journal of Endocrinology 2013216 T1-T15. (https://doi.org/10.1530/JOE-12-0498)

14 Kwon H \& Pessin JE. Adipokines mediate inflammation and insulin resistance. Frontiers in Endocrinology 20134 71. (https://doi. org/10.3389/fendo.2013.00071)

15 Cheng SP, Yin PH, Chang YC, Lee CH, Huang SY \& Chi CW. Differential roles of leptin in regulating cell migration in thyroid cancer cells. Oncology Reports 201023 1721-1727. (https://doi. org/10.3892/or_00000817)

16 Uddin S, Bavi P, Siraj AK, Ahmed M, Al-Rasheed M, Hussain AR, Ahmed M, Amin T, Alzahrani A, Al-Dayel F, et al. Leptin-R and its

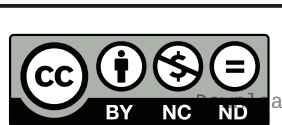

This work is licensed under a Creative Commons Attribution-NonCommercial-NoDerivatives 4.0 Internationab bicense.ifica.com at 04/26/2023 04:22:12AM 
association with PI3K/AKT signaling pathway in papillary thyroid carcinoma. Endocrine-Related Cancer 201017 191-202. (https://doi. org/10.1677/ERC-09-0153)

17 Kim WG, Park JW, Willingham MC \& Cheng SY. Diet-induced obesity increases tumor growth and promotes anaplastic change in thyroid cancer in a mouse model. Endocrinology 2013154 2936-2947. (https://doi.org/10.1210/en.2013-1128)

18 Li S, Shin HJ, Ding EL \& van Dam RM. Adiponectin levels and risk of type 2 diabetes: a systematic review and meta-analysis. JAMA 2009 302 179-188. (https://doi.org/10.1001/jama.2009.976)

19 Mitsiades N, Pazaitou-Panayiotou K, Aronis KN, Moon HS, Chamberland JP, Liu X, Diakopoulos KN, Kyttaris V, Panagiotou V, Mylvaganam G, et al. Circulating adiponectin is inversely associated with risk of thyroid cancer: in vivo and in vitro studies. Journal of Clinical Endocrinology and Metabolism 201196 E2023-E2028. (https:// doi.org/10.1210/jc.2010-1908)

20 Cheng SP, Liu CL, Hsu YC, Chang YC, Huang SY \& Lee JJ. Expression and biologic significance of adiponectin receptors in papillary thyroid carcinoma. Cell Biochemistry and Biophysics 201365 203-210. (https://doi.org/10.1007/s12013-012-9419-1)

21 Cibas ES \& Ali SZ. The 2017 Bethesda system for reporting thyroid cytopathology. Thyroid 201727 1341-1346. (https://doi.org/10.1089/ thy.2017.0500)

22 Matthews DR, Hosker JP, Rudenski AS, Naylor BA, Treacher DF \& Turner RC. Homeostasis model assessment: insulin resistance and beta-cell function from fasting plasma glucose and insulin concentrations in man. Diabetologia 198528 412-419. (https://doi. org/10.1007/BF00280883)

23 Muniyappa R, Lee S, Chen H \& Quon MJ. Current approaches for assessing insulin sensitivity and resistance in vivo: advantages, limitations, and appropriate usage. American Journal of Physiology: Endocrinology and Metabolism 2008294 E15-E26. (https://doi. org/10.1152/ajpendo.00645.2007)

24 Haugen BR, Alexander EK, Bible KC, Doherty GM, Mandel SJ Nikiforov YE, Pacini F, Randolph GW, Sawka AM, Schlumberger M et al. 2015 American Thyroid Association management guidelines for adult patients with thyroid nodules and differentiated thyroid cancer: the American Thyroid Association Guidelines Task Force on Thyroid Nodules and Differentiated Thyroid Cancer. Thyroid 201626 1-133. (https://doi.org/10.1089/thy.2015.0020)

25 Nardi F, Basolo F, Crescenzi A, Fadda G, Frasoldati A, Orlandi F, Palombini L, Papini E, Zini M, Pontecorvi A, et al. Italian consensus for the classification and reporting of thyroid cytology. Journal of Endocrinological Investigation 201437 593-599. (https://doi. org/10.1007/s40618-014-0062-0)

26 Edge SB, Byrd DR, Compton CC, Fritz AG, Greene F \& Trotti A. AJCC Cancer Staging Manual, 7th ed., pp 87-96. New York, NY, USA: Springer, 2010

27 Gharib H, Papini E, Garber JR, Duick DS, Harrell RM, Hegedüs L, Paschke R, Valcavi R, Vitti P \& AACE/ACE/AME Task Force on Thyroid Nodules. American Association of Clinical Endocrinologists, American College of Endocrinology, and Associazione Medici Endocrinologi Medical Guidelines for Clinical Practice for the diagnosis and management of thyroid nodules - 2016 update. Endocrine Practice 201622 622-639. (https://doi.org/10.4158/EP161208.GL)

28 Leenhardt L \& Grosclaude P. Epidemiology of thyroid carcinoma over the world. Annales d'Endocrinologie 201172 136-148. (https:// doi.org/10.1016/j.ando.2011.03.025)

29 Malaguarnera R, Vella V, Nicolosi ML \& Belfiore A. Insulin resistance: any role in the changing epidemiology of thyroid cancer? Frontiers in Endocrinology 20178 314. (https://doi.org/10.3389/ fendo.2017.00314)

30 Rezzonico JN, Rezzonico M, Pusiol E, Pitoia F \& Niepomniszcze H. Increased prevalence of insulin resistance in patients with differentiated thyroid carcinoma. Metabolic Syndrome and Related Disorders 20097 375-380. (https://doi.org/10.1089/met.2008.0062)
31 Bae MJ, Kim SS, Kim WJ, Yi YS, Jeon YK, Kim BH, Lee BJ, Lee JC, Kim IJ, Wang SG, et al. High prevalence of papillary thyroid cancer in Korean women with insulin resistance. Head and Neck 201638 66-71. (https://doi.org/10.1002/hed.23848)

32 Inoue $\mathrm{M} \&$ Tsugane $\mathrm{S}$. Insulin resistance and cancer: epidemiological evidence. Endocrine-Related Cancer 201219 F1-F8. (https://doi. org/10.1530/ERC-12-0142)

33 Catalan V, Gomez-Ambrosi J, Rodriguez A \& Fruhbeck G. Adipose tissue immunity and cancer. Frontiers in Physiology 20134275. (https://doi.org/10.3389/fphys.2013.00275)

34 Cunha LL, Marcello MA \& Ward LS. The role of the inflammatory microenvironment in thyroid carcinogenesis. Endocrine-Related Cancer 201421 R85-R103. (https://doi.org/10.1530/ERC-13-0431)

35 Dutta D, Ghosh S, Pandit K, Mukhopadhyay P \& Chowdhury S. Leptin and cancer: pathogenesis and modulation. Indian Journal of Endocrinology and Metabolism 201216 S596-S600. (https://doi. org/10.4103/2230-8210.105577)

36 Vansaun MN. Molecular pathways: adiponectin and leptin signalling in cancer. Clinical Cancer Research 201319 1926-1932. (https://doi. org/10.1158/1078-0432.CCR-12-0930)

37 Cheng SP, Chi CW, Tzen CY, Yang TL, Lee JJ, Liu TP \& Liu CL. Clinicopathologic significance of leptin and leptin receptor expressions in papillary thyroid carcinoma. Surgery 2010147 847-853. (https://doi.org/10.1016/j.surg.2009.11.004)

38 Cheng SP, Yin PH, Hsu YC, Chang YC, Huang SY, Lee JJ \& Chi CW. Leptin enhances migration of human papillary thyroid cancer cells through the PI3K/AKT and MEK/ERK signaling pathways. Oncology Reports 201126 1265-1271. (https://doi.org/10.3892/or.2011.1388)

39 Cheng SP, Liu CL, Hsu YC, Chang YC, Huang SY \& Lee JJ. Regulation of leptin receptor expression in human papillary thyroid cancer cells. Biomedicine and Pharmacotherapy 201266 469-473. (https://doi. org/10.1016/j.biopha.2012.03.008)

40 Zhang GA, Hou S, Han S, Zhou J, Wang X \& Cui W. Clinicopathological implications of leptin and leptin receptor expression in papillary thyroid cancer. Oncology Letters $2013 \mathbf{5}$ 797-800. (https://doi.org/10.3892/ol.2013.1125)

41 Yokota T, Oritani K, Takahashi I, Ishikawa J, Matsuyama A, Ouchi N, Kihara S, Funahashi T, Tenner AJ, Tomiyama Y, et al. Adiponectin, a new member of the family of soluble defense collagens, negatively regulates the growth of myelomonocytic progenitors and the functions of macrophages. Blood 200096 1723-1732.

42 Kumada M, Kihara S, Ouchi N, Kobayashi H, Okamoto Y, Ohashi K, Maeda K, Nagaretani H, Kishida K, Maeda N, et al. Adiponectin specifically increased tissue inhibitor of metalloproteinase-1 through interleukin-10 expression in human macrophages. Circulation 2004109 2046-2049. (https://doi.org/10.1161/01.CIR.0000127953.98131.ED)

43 Takemura Y, Ouchi N, Shibata R, Aprahamian T, Kirber MT, Summer RS, Kihara S \& Walsh K. Adiponectin modulates inflammatory reactions via calreticulin receptor-dependent clearance of early apoptotic bodies. Journal of Clinical Investigation $2007 \mathbf{1 1 7}$ 375-386. (https://doi.org/10.1172/JCI29709)

44 Yadav A, Kataria MA, Saini V \& Yadav A. Role of leptin and adiponectin in insulin resistance. Clinica Chimica Acta $2013 \mathbf{4 1 7}$ 80-84. (https://doi.org/10.1016/j.cca.2012.12.007)

45 Yamauchi T, Kamon J, Minokoshi Y, Ito Y, Waki H, Uchida S, Yamashita S, Noda M, Kita S, Ueki K, et al. Adiponectin stimulates glucose utilization and fatty-acid oxidation by activating AMPactivated protein kinase. Nature Medicine 20028 1288-1295. (https:// doi.org/10.1038/nm788)

46 Zakikhani M, Dowling RJ, Sonenberg N \& Pollak MN. The effects of adiponectin and metformin on prostate and colon neoplasia involve activation of AMP-activated protein kinase. Cancer Prevention Research 20081 369-375. (https://doi.org/10.1158/1940-6207.CAPR-08-0081)

47 Brakenhielm E, Veitonmäki N, Cao R, Kihara S, Matsuzawa Y, Zhivotovsky B, Funahashi T \& Cao Y. Adiponectin-induced antiangiogenesis and antitumor activity involve caspase-mediated 
endothelial cell apoptosis. PNAS 2004101 2476-2481. (https://doi. org/10.1073/pnas.0308671100)

48 Dalamaga M, Diakopoulos KN \& Mantzoros CS. The role of adiponectin in cancer: a review of current evidence. Endocrine Reviews 201233 547-594. (https://doi.org/10.1210/er.2011-1015)

49 Ucan B, Sahin M, Kizilgul M, Ozbek M, Ozdemir S, Calıskan M \& Cakal E. Serum ghrelin levels in papillary thyroid carcinoma. Archives of Endocrinology and Metabolism 201761 464-469. (https://doi. org/10.1590/2359-3997000000290)

50 Chopin L, Walpole C, Seim I, Cunningham P, Murray R, Whiteside E, Josh P \& Herington A. Ghrelin and cancer. Molecular and Cellular Endocrinology 2011340 65-69. (https://doi.org/10.1016/j. mce.2011.04.013)

51 Malendowicz W, Ziolkowska A, Szyszka M \& Kwias Z. Elevated blood active ghrelin and unaltered total ghrelin and obestatin concentrations in prostate carcinoma. Urologia Internationalis 2009 83 471-475. (https://doi.org/10.1159/000251190)

52 Markowska A, Ziółkowska A, Jaszczyńska-Nowinka K, Madry R \& Malendowicz LK. Elevated blood plasma concentrations of active ghrelin and obestatin in benign ovarian neoplasms and ovarian cancers. European Journal of Gynaecological Oncology 200930 518-522.

53 Samani AA, Yakar S, LeRoith D \& Brodt P. The role of the IGF system in cancer growth and metastasis: overview and recent insights. Endocrine Reviews 200728 20-47. (https://doi.org/10.1210/ er.2006-0001)
54 Delhanty PJ, Neggers SJ \& van der Lely AJ. Des-acyl ghrelin: a metabolically active peptide. Endocrine Development 201325 112-121. (https://doi.org/10.1159/000346059)

55 Cassoni P, Allia E, Marrocco T, Ghè C, Ghigo E, Muccioli G \& Papotti M. Ghrelin and cortistatin in lung cancer: expression of peptides and related receptors in human primary tumors and in vitro effect on the H345 small cell carcinoma cell line. Journal of Endocrinological Investigation 200629 781-790. (https://doi.org/10.1007/BF03347371)

56 Camiña JP, Campos JF, Caminos JE, Dieguez C \& Casanueva FF. Obestatin-mediated proliferation of human retinal pigment epithelial cells: regulatory mechanisms. Journal of Cellular Physiology 2007211 1-9. (https://doi.org/10.1002/jcp.20925)

57 Pazos Y, Alvarez CJ, Camiña JP \& Casanueva FF. Stimulation of extracellular signal-regulated kinases and proliferation in the human gastric cancer cells Kato-III by obestatin. Growth Factors 200725 373-381. (https://doi.org/10.1080/08977190801889313)

58 Volante M, Rosas R, Ceppi P, Rapa I, Cassoni P, Wiedenmann B, Settanni F, Granata R \& Papotti M. Obestatin in human neuroendocrine tissues and tumours: expression and effect on tumour growth. Journal of Pathology 2009218 458-466. (https://doi. org/10.1002/path.2551)

59 Gurgul E, Kasprzak A, Blaszczyk A, Biczysko M, Surdyk-Zasada J, Seraszek-Jaros A \& Ruchala M. Ghrelin and obestatin in thyroid gland - immunohistochemical expression in nodular goiter, papillary and medullary cancer. Folia Histochemica et Cytobiologica 201553 19-25. (https://doi.org/10.5603/FHC.a2015.0004)

Received in final form 27 May 2019

Accepted 17 June 2019

Accepted Preprint published online 17 June 2019 https://ec.bioscientifica.com https://doi.org/10.1530/EC-19-0262 (c) 2019 The authors Published by Bioscientifica Ltd
This work is licensed under a Creative Commons Attribution-NonCommercial-NoDerivatives 4.0 Internationab sicense.ifica . com at 04/26/2023 04:22:12AM 